\title{
Evaluation of the efficacy of antifungal drugs against Paracoccidioides brasiliensis and Paracoccidioides lutzii in a Galleria mellonella model
}

\author{
Junya de Lacorte Singulani, Liliana Scorzoni, Ana Carolina Alves de Paula e Silva, \\ Ana Marisa Fusco-Almeida, Maria José Soares Mendes-Giannini *
}

Faculdade de Ciências Farmacêuticas, Universidade Estadual Paulista (UNESP), Rodovia Araraquara-Jaú Km 1, Araraquara, São Paulo CEP: 14801-902, Brazil

\section{A R T I C L E I N F O}

\section{Article history:}

Received 21 January 2016

Accepted 22 May 2016

\section{Keywords:}

Alternative animal model

Antifungals

Efficacy

Paracoccidioidomycosis

\begin{abstract}
A B S T R A C T
Paracoccidioides brasiliensis and P. lutzii belong to a group of thermodimorphic fungi and cause paracoccidioidomycosis (PCM), which is a human systemic mycosis endemic in South and Central America. Patients with this mycosis are commonly treated with amphotericin B (AmB) and azoles. The study of fungal virulence and the efficacy and toxicity of antifungal drugs has been successfully performed in a Galleria mellonella infection model. In this work, G. mellonella larvae were infected with two Paracoccidioides spp. and the efficacy and toxicity of AmB and itraconazole were evaluated in this model for the first time. $A m B$ and itraconazole treatments were effective in increasing larval survival and reducing the fungal burden. The fungicidal and fungistatic effects of AmB and itraconazole, respectively, were observed in the model. Furthermore, these effects were independent of changes in haemocyte number. G. mellonella can serve as a rapid model for the screening of new antifungal compounds against Paracoccidioides and can contribute to a reduction in experimental animal numbers in the study of PCM.
\end{abstract}

(C) 2016 Elsevier B.V. and International Society of Chemotherapy. All rights reserved.

\section{Introduction}

Paracoccidioides brasiliensis belongs to a group of thermodimorphic fungi that is found in the form of mycelia at room temperature $\left(25-27^{\circ} \mathrm{C}\right)$ and in yeast form at body temperature $\left(37^{\circ} \mathrm{C}\right)$. Phylogenetic studies showed the existence of three different phylogenetic species of $P$. brasiliensis (S1, PS2 and PS3) [1]. More recently, genomic studies showed that $P$. brasiliensis strain 01 could not be included in these groups and was considered a new species, termed $P$. lutzii $[2,3]$. The individual characteristics of each species have implications in the diagnosis, clinical manifestations and treatment of the disease [4].

Paracoccidioides spp. causes paracoccidioidomycosis (PCM), a human systemic mycosis whose clinical importance has increased due to the frequency, severity of their anatomical and clinical forms, and mortality rate. PCM is endemic in South and Central America, among which Brazil, Venezuela, Colombia and Argentina are the countries with the highest number of cases. In these regions, the annual incidence rate of new cases ranges from 1 to 3 per $10^{5}$ inhabitants. In Brazil, PCM is the eighth most important cause of

\footnotetext{
* Corresponding author. Faculdade de Ciências Farmacêuticas, Universidade Estadual Paulista (UNESP), Rodovia Araraquara-Jaú Km 1, Araraquara, São Paulo CEP: 14801-902, Brazil. Fax: +55 16 3322-0073.

E-mail addresses: gianninimj@gmail.com; giannini@fcfar.unesp.br (M.J.S. MendesGiannini).
}

mortality from chronic infectious diseases, with 1.65 deaths per $10^{6}$ inhabitants. In non-endemic regions such as the USA, Europe and Asia, some imported cases have been reported. The marked predominance of clinical disease is in adult men, rural workers and the immunocompromised [5-7].

Paracoccidioides infection occurs upon inhalation of propagules by the host. These structures then invade terminal airways, where they differentiate into yeast forms. Temperature is essential for this transformation. The lung is the first site of infection, but the yeast can spread to other organs. It is speculated that modulation of host cell apoptosis is advantageous for the fungi because the micro-organisms can evade the killing activity of the phagocytic antimicrobial machinery in tissues; this would prevent their death, and the fungi could disseminate through the host's circulatory system and stimulate the inflammatory response to invade tissues as a consequence of these injures [8]. There is evidence that $P$. brasiliensis is able to modulate the chronic inflammatory response through nitric oxide (NO), which improves tissue degradation and/or decreases extracellular matrix synthesis by controlling inflammatory and immune mediators. In the later phase of PCM, the deleterious effects of NO may be associated with loose granulomas and high fungal dissemination [9,10]. Treatment of PCM takes place over long periods of time and depends on the severity in each patient: azoles (itraconazole, fluconazole and voriconazole) and sulfonamides are options for mild-to-moderate clinical forms; and amphotericin $\mathrm{B}(\mathrm{AmB})$ is used for severe and disseminated cases $[6,7,11]$. 
Virulence studies of different fungi such as P. brasiliensis, P. lutzii, Histoplasma capsulatum [12,13], Cryptococcus neoformans [14], Fusarium spp. [15], Candida [16,17] and Trichosporon spp. [18] have been successfully performed in a Galleria mellonella infection model. It has important advantages as a fungal host study model: larvae can be incubated at temperatures between $25^{\circ} \mathrm{C}$ and $37^{\circ} \mathrm{C}$, enabling the habitat and conditions of infection in mammals to be simulated; exact amounts of pathogens can be administered; and the viability of the larvae can easily be detected by the lack of movement and melanisation response after infection [19]. Furthermore, larvae have six important types of cells in the defence system called haemocytes, which are classified as prohaemocytes, plasmatocytes, granulocytes, coagulocytes, spherulocytes and oenocytoids. The plasmatocytes and granulocytes participate in phagocytosis, nodule formation, encapsulation and defence against microbial pathogens $[20,21]$. G. mellonella has also been used to test the efficacy and toxicity of commercial and new antifungals [22-24].

In this work, G. mellonella was infected with two species of Paracoccidioides and the efficacy and toxicity of AmB and itraconazole were evaluated in this model for the first time.

\section{Materials and methods}

\subsection{Fungi}

P. brasiliensis isolate 18 (chronic PCM; São Paulo, Brazil) and P. lutzii Pb01-like strain ATCC MYA-826 (acute PCM; Goiânia, Brazil) were grown in Fava Netto medium (prepared in-house) at $37^{\circ} \mathrm{C}$ for $4-5$ days. Fungi were transferred to brain-heart infusion (BHI) (Neogen, Lansing, MI) broth supplemented with $1 \%$ glucose (Hexapur, Solon, $\mathrm{OH}$ ) and were grown on an shaker (New Brunswick, Edison, NJ) for 3-4 days at $150 \mathrm{rpm}$ and $37^{\circ} \mathrm{C}$. For the experiment, yeast cells were washed three times with phosphate-buffered saline (PBS) (prepared in-house) containing $20 \mathrm{mg} / \mathrm{L}$ ampicillin (Sigma-Aldrich, St Louis, MO) to prevent bacterial contamination.

\subsection{Insects}

Eggs of G. mellonella (Lepidoptera: Pyralidae) were provided by Dr Carlos Eduardo Winter (Universidade de São Paulo, São Paulo, Brazil) to initiate the culture of this insect in our laboratory. Larvae were kept in plastic boxes and were reared on honeybee wax and pollen at $25^{\circ} \mathrm{C}$ in darkness. Larvae of ca. $150 \mathrm{mg}$ were selected for the experiments and were kept without food in Petri plates at $37{ }^{\circ} \mathrm{C}$ in the dark for $24 \mathrm{~h}$ prior to use.

\subsection{Survival analysis}

Before injection, the pro-leg area was cleaned with 70\% ethanol. Each larvae group was inoculated using a Hamilton syringe through the last left pro-leg with $10 \mu \mathrm{L}$ of $1 \times 10^{5}, 5 \times 10^{5}, 5 \times 10^{6}$ or $5 \times 10^{6}$ $P$. brasiliensis or $P$. lutzii yeast cells. The inoculum of $5 \times 10^{6}$ yeast cells/ larva was used for the remaining studies. A group of uninfected larvae and a group of uninfected larvae inoculated with PBS were used as controls in all experiments. Larvae were incubated in Petri plates at $37^{\circ} \mathrm{C}$ and were assessed at 7 days for lack of physical movement. A total of 16 larvae were used for each condition, and each experiment was replicated three times.

\subsection{Efficacy and toxicity assays}

At $1 \mathrm{~h}$ after infection with Paracoccidioides spp., larvae were injected with $10 \mu \mathrm{L}$ of $\mathrm{AmB}$ (Sigma-Aldrich) at $0.5,1$ or $2 \mathrm{mg} / \mathrm{kg}$ or with itraconazole (Sigma-Aldrich) at 5.5, 11, 22 and $44 \mathrm{mg} / \mathrm{kg}$ through the last right pro-leg. Stock solutions of AmB and itraconazole were prepared in dimethyl sulfoxide (DMSO) (Labsynth, Diadema, SP,
Brazil) and were diluted in PBS to a DMSO concentration of 5\%. Groups of uninfected larvae were treated with antifungals alone and with the vehicles to test their toxicity. Larvae were incubated at $37^{\circ} \mathrm{C}$ and were assessed for 7 days for lack of physical movement.

\subsection{Fungal burden}

At 1, 48 and 96 h post-treatment with AmB or itraconazole, larvae from each group were surface-sterilised in 70\% ethanol. A group of infected larvae without treatment was also used. Each larva was cut into small pieces with a scalpel and was suspended in $1 \mathrm{~mL}$ of PBS with $20 \mathrm{mg} / \mathrm{L}$ ampicillin. The tissues were transferred to conical tubes with glass beads and were homogenised using a vortex mixer (Norte Científica, Araraquara, SP, Brazil). Each sample was diluted 100× in PBS and then $100 \mu \mathrm{L}$ of the resulting dilution was plated on BHI agar supplemented with $4 \%$ horse serum, $5 \%$ P. brasiliensis 339 culture filtrate and $40 \mathrm{mg} / \mathrm{L}$ gentamicin [25]. The plates were incubated at $37^{\circ} \mathrm{C}$ for 10 days and then CFU of P. brasiliensis or P. lutzii were counted.

\subsection{Histological evaluation}

At $48 \mathrm{~h}$ post-treatment with AmB or itraconazole, larvae from each group were fixed by immersion in phosphate-buffered $4 \%$ formalin. A group of uninfected larvae and a group of infected larvae without treatment were also used. Samples were embedded in paraffin, were serially sectioned at a thickness of $5 \mu \mathrm{m}$ and were stained using Periodic acid-Schiff (PAS) solution (Sigma-Aldrich). Images were analysed using an optical microscope (ZEISS AxioCam HRc; Carl Zeiss Microscopy GmbH, Jena, Germany) at $40 \times$.

\subsection{Haemocyte density}

At $1 \mathrm{~h}$ and $48 \mathrm{~h}$ post-treatment with $\mathrm{AmB}$ or itraconazole, haemolymph samples were collected by puncturing the larval abdomen and were diluted in ice-cold PBS (1:20). Then, $10 \mu \mathrm{L}$ aliquots of the haemocyte suspension were added to a Neubauer chamber (haemocytometer) and cells were counted in four main squares under a brightfield microscope. As the larvae without treatment were debilitated or dead at $96 \mathrm{~h}$, it was not possible to acquire sufficient amount of haemolymph for analysis.

\subsection{Statistical analysis}

Survival curves were analysed using the log-rank (MantelCox) test in GraphPad Prism 5 (GraphPad Software Inc., La Jolla, CA). Fungal burden and haemocyte density were analysed using analysis of variance (ANOVA) with the Bonferroni post-test. A $P$ value of $<0.05$ was considered statistically significant.

\section{Results}

3.1. Killing of G. mellonella by Paracoccidioides spp. and the effect of antifungal agents

To determine whether G. mellonella larvae were a suitable model for studying Paracoccidioides pathogenesis, its infection characteristics were first defined. Larval killing was dependent on the number of Paracoccidioides cells injected. Very few G. mellonella larvae were killed with $\leq 1 \times 10^{6}$ yeast cells/larva within the period of infection (data not shown), whereas most of the G. mellonella larvae were killed with $5 \times 10^{6}$ yeast cells/larva, which was the concentration selected for testing the antifungal treatments.

At the end of 7 days, $11 \%$ and $4 \%$ of the larvae infected with $5 \times 10^{6}$ yeast cells/larva of $P$. brasiliensis or $P$. lutzii survived, respectively. All doses of AmB $(0.5,1$ and $2 \mathrm{mg} / \mathrm{kg}$ ) protected G. mellonella from 

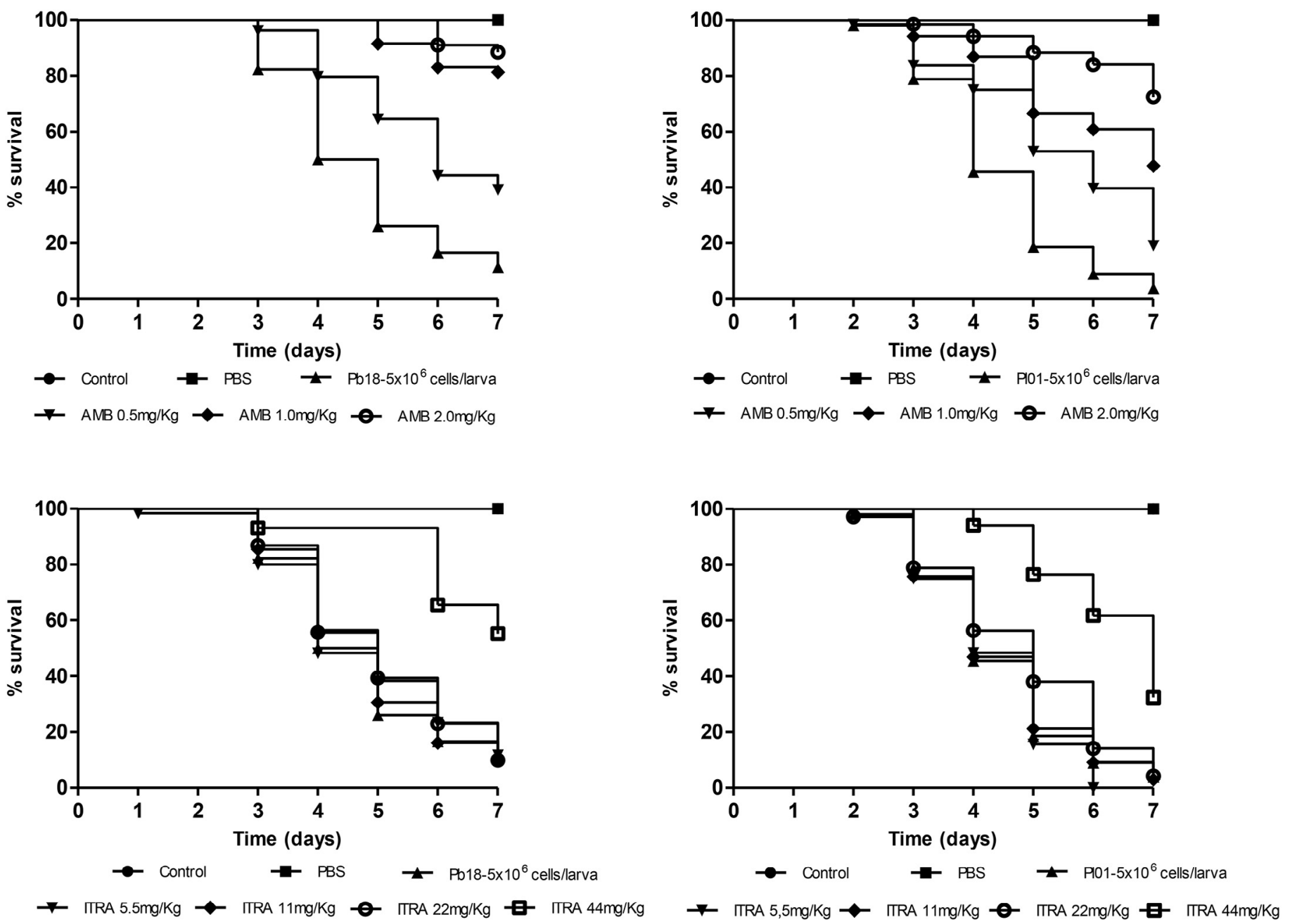

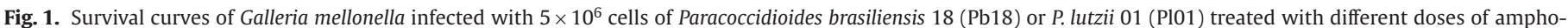

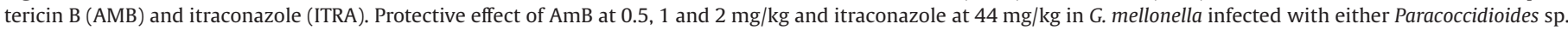
( $n=40-50)$. PBS, phosphate-buffered saline.

infection with either Paracoccidioides spp. in a dose-dependent manner $(P<0.0001)$. Survival rates of $39 \%, 81 \%$ and $88 \%$ in larvae infected with $P$. brasiliensis treated with $0.5,1$ and $2 \mathrm{mg} / \mathrm{kg} \mathrm{AmB}$, respectively, were observed. For larvae infected with $P$. lutzii, $19 \%$, $48 \%$ and $72 \%$ survived after treatment with doses of $0.5,1$ and $2 \mathrm{mg} /$ $\mathrm{kg} \mathrm{AmB}$, respectively. Itraconazole did not protect the larvae from infection with either Paracoccidioides spp. at doses of 5.5, 11 and $22 \mathrm{mg} / \mathrm{kg}$, but increased the survival of larvae infected with $P$. brasiliensis to 55\% and the survival of larvae infected with $P$. lutzii to $32 \%$ at a dose of $44 \mathrm{mg} / \mathrm{kg}(P<0.0001)$ (Fig. 1$)$. Moreover, neither $5 \%(\mathrm{v} / \mathrm{v})$ DMSO as a control nor the antifungal compounds in the tested doses were toxic to the larvae.

\subsection{Fungal burden in the tissues of $\mathrm{G}$. mellonella}

Subsequently, some of the larvae infected with $P$. brasiliensis and $P$. lutzii treated with $2 \mathrm{mg} / \mathrm{kg} \mathrm{AmB}$ and $44 \mathrm{mg} / \mathrm{kg}$ itraconazole were selected for evaluation of the fungal burden over time, specifically at 1, 48 and $96 \mathrm{~h}$ after treatment. These doses of antifungal drugs were chosen because they demonstrated the greatest increase in larvae survival. CFUs with a cerebriform aspect, cream-coloured and not adhering to the medium were isolated. Fig. 2 shows that treatment with AmB and itraconazole significantly reduced the number of CFU in the larvae after the first hour of treatment $(P<0.05$ for both cases). Moreover, in the AmB group, CFU were very low and could be not detected after $96 \mathrm{~h}$ of treatment by the plating method, whereas the itraconazole group presented non-detectable CFU after $1 \mathrm{~h}$ treatment followed by an increase in the fungal burden thereafter.

Some larvae that were uninfected and infected with Paracoccidioides spp. and treated with $2 \mathrm{mg} / \mathrm{kg}$ AmB or $44 \mathrm{mg} / \mathrm{kg}$ itraconazole were also selected for histological evaluation. PASstained sections showed that both $P$. brasiliensis and $P$. lutzii were present mainly under the cuticle and in the peripheral adipose bodies. It was possible to observe large aggregates of fungi with haemocyte recruitment and melanisation spots. Treatment with AmB and itraconazole reduced the number of CFU, and small aggregates could be observed in the peripheral adipose bodies of larvae (Fig. 3).

\subsection{Haemocyte density in infection and after treatment}

Fig. 4 shows that infection with $5 \times 10^{6}$ yeast cells/larva of $P$. brasiliensis or $P$. lutzii significantly reduced the haemocyte density after infection $(1 \mathrm{~h})$ and that the density remained the same after $48 \mathrm{~h}$ compared with uninfected larvae. Treatment with $2 \mathrm{mg} / \mathrm{kg} \mathrm{AmB}$ or $44 \mathrm{mg} / \mathrm{kg}$ itraconazole did not change the number of haemocytes at the evaluated times. 

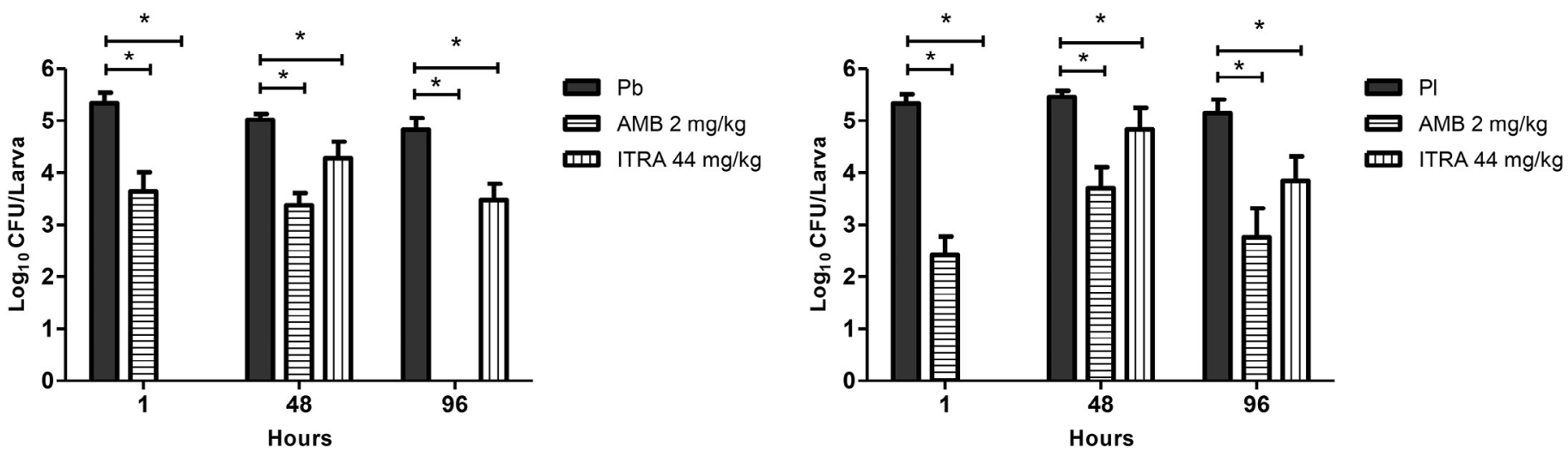

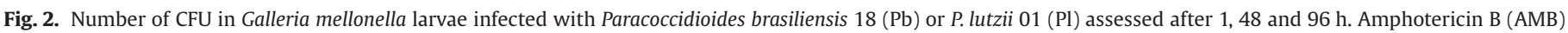
$2 \mathrm{mg} / \mathrm{kg}$ and itraconazole (ITRA) $44 \mathrm{mg} / \mathrm{kg}$ reduced the number of CFU. ${ }^{*} \mathrm{P}<0.05$ vs. infected group (Pb or Pl) $(n=6)$.

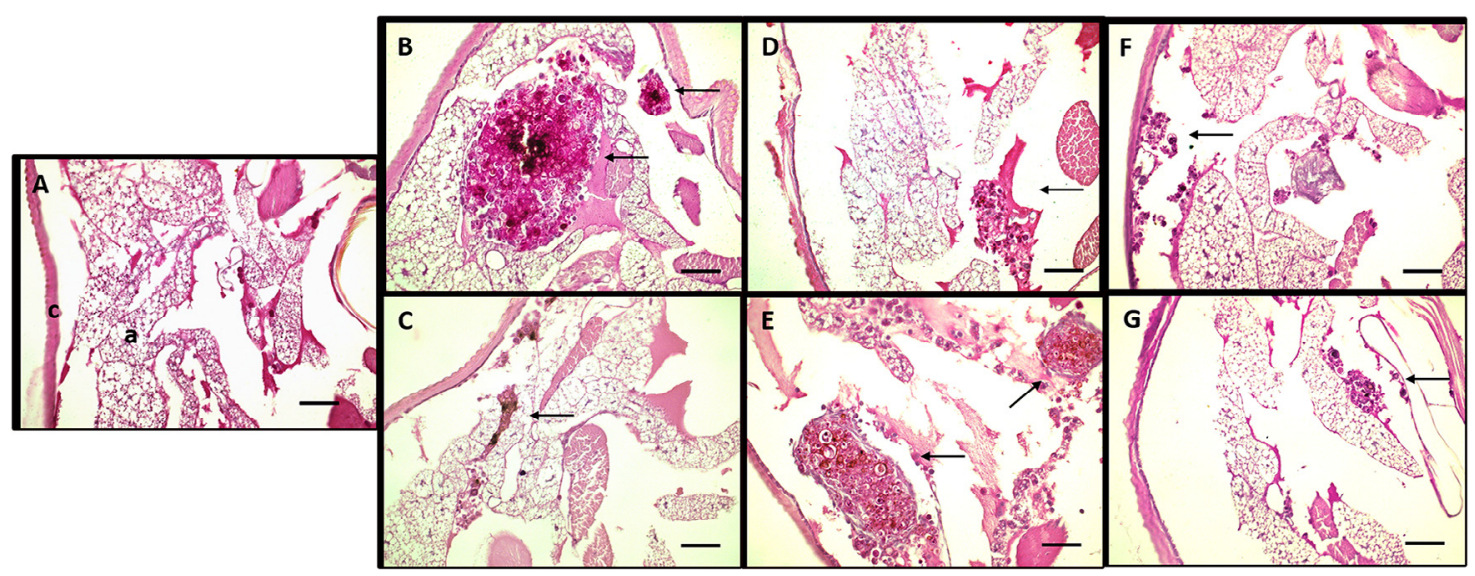

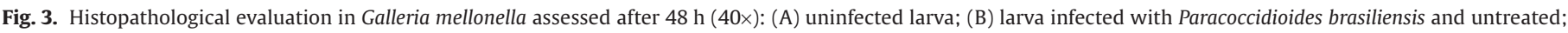

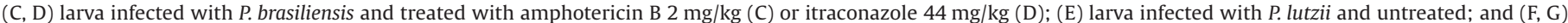

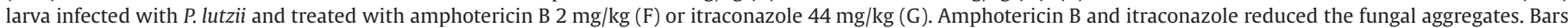

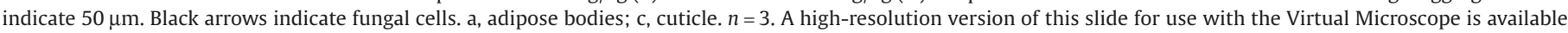
as eSlide: VM02703.
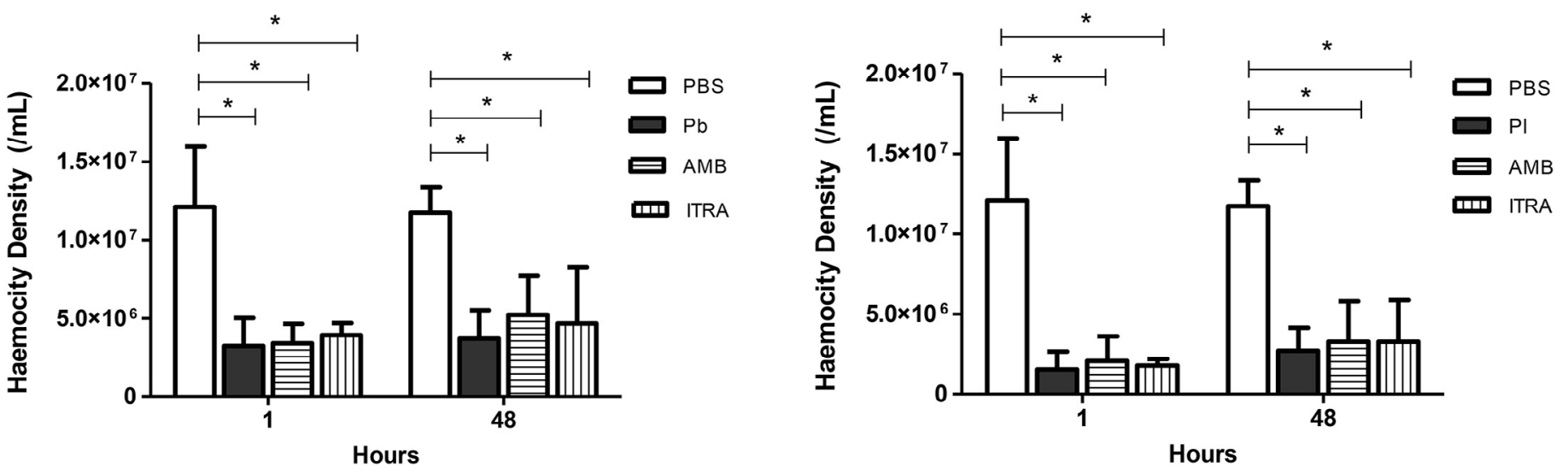

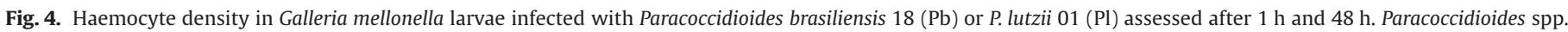

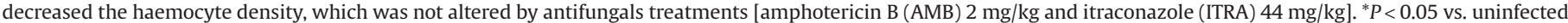
group (PBS control) $(n=6)$. PBS, phosphate-buffered saline.

\section{Discussion}

Because of the high cost and for ethical reasons, the principles of the three Rs (refinement, reduction, replacement) have been applied to reduce the use of experimental mammals to the minimum necessary [26]. In this context, the use of alternative animal models has been increasingly accepted and used for the study of fungushost interactions as well as efficacy and toxicity of antifungals. 
Recently, a G. mellonella infection model was shown to be capable of evaluating infections caused by $P$. lutzii and P. brasiliensis [12,13]. An important advantage of G. mellonella for the study of thermally dimorphic fungi such as Paracoccidioides sp. over other invertebrate hosts such as Caenorhabditis elegans is its ability to be maintained at a temperature of $37^{\circ} \mathrm{C}$. However, there are no previous studies with antifungal agents in this G. mellonellaParacoccidioides model. Using G. mellonella larvae as a model permits faster studies of the disease and its treatment. Typically, studies of virulence and antifungal efficacy against Paracoccidioides spp. have been performed in murine models, but one of the limitations is the long time required for the experiment (usually 30 days for the infection and 30 days for treatment).

To evaluate whether the G. mellonella-Paracoccidioides spp. model could be used to study antifungal drugs, the role of the most commonly used agents for PCM was investigated. In vitro, AmB presented minimum inhibitory concentrations (MICs) of $0.12 \mathrm{mg} / \mathrm{L}$ and $0.06 \mathrm{mg} /$ $\mathrm{L}$, and itraconazole presented MICs of $0.015 \mathrm{mg} / \mathrm{L}$ and $0.008 \mathrm{mg} / \mathrm{L}$ for $P$. brasiliensis isolate 18 and $P$. lutzii strain 01 , respectively [27]. In the clinic, intravenous amphotericin has been used for severe cases of PCM at a dose of $1 \mathrm{mg} / \mathrm{kg} /$ day, and oral itraconazole is considered the best option for mild-to-moderate clinical forms at $200 \mathrm{mg} /$ day for 6-18 months [7].

First we showed that $5 \times 10^{6} \mathrm{CFU} /$ larva was a suitable inoculum both for $P$. brasiliensis and $P$. lutzii to establish a lethal infection in the G. mellonella model in order to evaluate antifungal agents. At this concentration, most of the larvae died at the end of the 7-day incubation period. Furthermore, the survival curve profiles for both species were similar in this model, as previously described [13]. In most other studies, antifungal drugs were administered within the first $4 \mathrm{~h}$ post-infection $[16,18,22,28]$ and we choose to administer $\mathrm{AmB}$ and itraconazole at $1 \mathrm{~h}$ post-infection. Following administration of AmB at $0.5,1$ or $2 \mathrm{mg} / \mathrm{kg}$, a dose-dependent survival curve was produced. This is in contrast to itraconazole, for which only the highest dose $(44 \mathrm{mg} / \mathrm{kg}$ ) increased the survival of the infected larvae.

G. mellonella has been used to evaluate the toxicity of compounds and solvents $[28,29]$. In parallel to the experiments for efficacy, the drugs AmB or itraconazole alone and the solvent DMSO were tested and showed no toxicity to larvae.

Second, the fungal burden of larvae infected with Paracoccidioides spp. was evaluated. In previous work with the G. mellonella model, the growth of $P$ utzii from larvae using BHI agar plus antibiotics was not observed [12]. In this study, horse serum and P. brasiliensis 339 culture filtrate were added, which are important factors for the growth of Paracoccidioides colonies in mammalian models [25], and Paracoccidioides species were successfully recovered from larvae at the end of the experiment using this medium. AmB $(2 \mathrm{mg} / \mathrm{kg})$ and itraconazole $(44 \mathrm{mg} / \mathrm{kg}$ ) treatments were effective in the reducing the fungal burden. AmB has been shown to be effective against Candida albicans, C. krusei [16], C. neoformans [14] and Fusarium spp. [15] in G. mellonella models at a dose range of $1-4 \mathrm{mg} / \mathrm{kg}$ with a single administration. However, in these cases the fungal burden was evaluated at a single time point, whereas in the current study the fungal burden was evaluated at three different times (1,48 and $96 \mathrm{~h})$ and a fungicidal effect of $\mathrm{AmB}$ was observed in larvae. Conversely, a previous study did not observe a fungicidal effect in this model against a strain of $C$. tropicalis [17]. Azoles such as fluconazole and voriconazole have also shown activity against $C$. neoformans and Candida spp., respectively, in G. mellonella larvae [14,16]. Previously, itraconazole was tested at a dose of $100 \mathrm{mg} / \mathrm{kg}$ in combination with inhibitors of calcium signalling against Aspergillus fumigatus in G. mellonella [30]. In the current work, the efficacy of itraconazole alone at a dose of $44 \mathrm{mg} / \mathrm{kg}$ in infected larvae was investigated and a fungistatic effect was observed. However, further studies to evaluate the pharmacokinetics could be useful for understanding the bioavailability and effectiveness of these drugs in the G. mellonella model.
Fungi were also observed in the tissues of larvae through histopathologic analyses. Aggregates with fungal cells, haemocytes and structures such as granulomas were shown in other studies with G. mellonella-Paracoccidioides spp. [12,13] and in the lungs and oral lesions of mammals with PCM [31-33]. Treatment with AmB or itraconazole demonstrated the ability to reduce aggregates of fungi in the adipose bodies of $G$. mellonella, as also observed in mammalian models [34,35].

Another parameter evaluated in this study was the haemocyte density. The role of haemocytes in the immune response is similar to the innate immune response of mammals against pathogens. Furthermore, variation in the density of these cells is related to the pathogenicity of the fungus [21]. Infection by P. brasiliensis or P. lutzii decreased the haemocyte density in the haemolymph of larvae significantly. Such behaviour was also observed when G. mellonella larvae were infected with C. albicans and C. krusei and can be explained by two possibilities: the haemocytes migrate from the haemolymph to the tissues; and infection with intracellular parasites leads to phagocytosis and subsequent lysis of haemocytes $[13,16]$. Some studies have shown the immunomodulatory role of antifungals such as AmB, caspofungin and micafungin [36-38], but treatment with either AmB or itraconazole had no effect the number of haemocytes in infected larvae in the present study.

\section{Conclusions}

The results showed that G. mellonella larvae are a useful model for evaluating infection by different Paracoccidioides spp. and their response to different antifungal agents. Although $P$. brasiliensis and $P$. lutzii present different morphological and genetic characteristics, the survival curve profiles and response to $\mathrm{AmB}$ and itraconazole were similar in the G. mellonella model, which suggests important implications for the clinical treatment of PCM. Furthermore, a possible fungicidal effect of $\mathrm{AmB}$ and a fungistatic effect of itraconazole were observed. These effects were independent of haemocyte density changes. Finally, G. mellonella can serve as a rapid model to test other isolates of Paracoccidioides and can be used to screen new antifungal compounds against this fungi, which could subsequently help reduce the number of mammals used for PCM experimentation.

Funding: This work was supported by Conselho Nacional de Pesquisa e Desenvolvimento (CNPq), Fundação de Amparo à Pesquisa do Estado de São Paulo (FAPESP) [2015/03700-9, 2014/10446-9 and 2013/10917-9], Coordenação de Aperfeiçoamento de Pessoal de Nível Superior (CAPES) and Programa de Apoio ao Desenvolvimento Científico da Faculdade de Ciências Farmacêuticas da UNESP (PADC/FCF).

Competing interests: None declared.

Ethical approval: Not required.

\section{References}

[1] Matute DR, McEwen JG, Puccia R, Montes BA, San-Blas G, Bagagli E, et al. Cryptic speciation and recombination in the fungus Paracoccidioides brasiliensis as revealed by gene genealogies. Mol Biol Evol 2006;23:65-73.

[2] Teixeira MM, Theodoro RC, de Carvalho MJ, Fernandes L, Paes HC, Hahn RC, et al. Phylogenetic analysis reveals a high level of speciation in the Paracoccidioides genus. Mol Phylogenet Evol 2009;52:273-83.

[3] Carrero LL, Niño-Vega G, Teixeira MM, Carvalho MJ, Soares CM, Pereira M, et al New Paracoccidioides brasiliensis isolate reveals unexpected genomic variability in this human pathogen. Fungal Genet Biol 2008;45:605-12.

[4] Teixeira MM, Theodoro RC, Oliveira FF, Machado GC, Hahn RC, Bagagli E, et al. Paracoccidioides lutzii sp. nov.: biological and clinical implications. Med Mycol 2014;52:19-28.

[5] Coutinho ZF, Silva D, Lazera M, Petri V, Oliveira RM, Sabroza PC, et al. Paracoccidioidomycosis mortality in Brazil (1980-1995). Cad Saude Publica 2002;18:1441-54.

[6] Bocca AL, Amaral AC, Teixeira MM, Sato PK, Sato P, Shikanai-Yasuda MA, et al. Paracoccidioidomycosis: eco-epidemiology, taxonomy and clinical and therapeutic issues. Future Microbiol 2013;8:1177-91. 
[7] Shikanai-Yasuda MA, Telles Filho FQ, Mendes RP, Colombo AL, Moretti ML. Guidelines in paracoccidioidomycosis. Rev Soc Bras Med Trop 2006;39:297-310 [in Portuguese].

[8] Silva JF, Vicentim J, Oliveira HC, Marcos CM, Assato PA, Andreotti PF, et al. Influence of the Paracoccidioides brasiliensis 14-3-3 and gp43 proteins on the induction of apoptosis in A549 epithelial cells. Mem Inst Oswaldo Cruz 2015;110:476-84.

[9] Nishikaku AS, Molina RF, Ribeiro LC, Scavone R, Albe BP, Cunha CS, et al. Nitric oxide participation in granulomatous response induced by Paracoccidioides brasiliensis infection in mice. Med Microbiol Immunol 2009;198:123-35.

[10] Bernardino S, Pina A, Felonato M, Costa TA, Frank de Araújo E, Feriotti C, et al. TNF- $\alpha$ and CD8+ T cells mediate the beneficial effects of nitric oxide synthase- 2 deficiency in pulmonary paracoccidioidomycosis. PLoS Negl Trop Dis 2013;7:e2325.

[11] Queiroz-Telles F, Escuissato DL. Pulmonary paracoccidioidomycosis. Semin Respir Crit Care Med 2011;32:764-74.

[12] Thomaz L, García-Rodas R, Guimarães AJ, Taborda CP, Zaragoza O, Nosanchuk JD. Galleria mellonella as a model host to study Paracoccidioides lutzii and Histoplasma capsulatum. Virulence 2013;4:139-46.

[13] Scorzoni L, de Paula e Silva AC, Singulani JL, Leite FS, de Oliveira HC, da Silva RA, et al. Comparison of virulence between Paracoccidioides brasiliensis and Paracoccidioides lutzii using Galleria mellonella as a host model. Virulence 2015;6:766-76.

[14] Mylonakis E, Moreno R, El Khoury JB, Idnurm A, Heitman J, Calderwood SB, et al. Galleria mellonella as a model system to study Cryptococcus neoformans pathogenesis. Infect Immun 2005;73:3842-50.

[15] Coleman JJ, Muhammed M, Kasperkovitz PV, Vyas JM, Mylonakis E. Fusarium pathogenesis investigated using Galleria mellonella as a heterologous host. Fungal Biol 2011;115:1279-89.

[16] Scorzoni L, de Lucas MP, Mesa-Arango AC, Fusco-Almeida AM, Lozano E, Cuenca-Estrella M, et al. Antifungal efficacy during Candida krusei infection in non-conventional models correlates with the yeast in vitro susceptibility profile. PLoS ONE 2013;8:e60047.

[17] Mesa-Arango AC, Forastiero A, Bernal-Martínez L, Cuenca-Estrella M, Mellado E, Zaragoza O. The non-mammalian host Galleria mellonella can be used to study the virulence of the fungal pathogen Candida tropicalis and the efficacy of antifungal drugs during infection by this pathogenic yeast. Med Mycol 2013;51:461-72.

[18] Mariné M, Bom VL, de Castro PA, Winkelstroter LK, Ramalho LN, Brown NA, et al. The development of animal infection models and antifungal efficacy assays against clinical isolates of Trichosporon asahii, T. asteroides and T. inkin. Virulence 2015;6:476-86.

[19] Fuchs BB, Mylonakis E. Using non-mammalian hosts to study fungal virulence and host defense. Curr Opin Microbiol 2006;9:346-51.

[20] Tojo S, Naganuma F, Arakawa K, Yokoo S. Involvement of both granular cells and plasmatocytes in phagocytic reactions in the greater wax moth, Galleria mellonella. J Insect Physiol 2000;46:1129-35.

[21] Bergin D, Brennan M, Kavanagh K. Fluctuations in haemocyte density and microbial load may be used as indicators of fungal pathogenicity in larvae of Galleria mellonella. Microbes Infect 2003;5:1389-95.

[22] Favre-Godal Q, Dorsaz S, Queiroz EF, Conan C, Marcourt L, Wardojo BP, et al. Comprehensive approach for the detection of antifungal compounds using a susceptible strain of Candida albicans and confirmation of in vivo activity with the Galleria mellonella model. Phytochemistry 2014;105:68-78.

[23] Lionakis MS. Drosophila and Galleria insect model hosts: new tools for the study of fungal virulence, pharmacology and immunology. Virulence 2011;2:521-7.

[24] Mircus G, Albert N, Ben-Yaakov D, Chikvashvili D, Shadkchan Y, Kontoyiannis $\mathrm{DP}$, et al. Identification and characterization of a novel family of selective antifungal compounds (CANBEFs) that interfere with fungal protein synthesis. Antimicrob Agents Chemother 2015;59:5631-40.

[25] Granzoto DS, Vitali LH, Martinez R. Efficacy of voriconazole in experimental rat paracoccidioidomycosis. Rev Soc Bras Med Trop 2013;46:79-83.

[26] Hartung T. Lessons learned from alternative methods and their validation for a new toxicology in the 21st century. J Toxicol Environ Health B Crit Rev 2010;13:277-90.

[27] de Paula e Silva AC, Oliveira HC, Silva JF, Sangalli-Leite F, Scorzoni L, Fusco-Almeida AM, et al. Microplate alamarBlue assay for Paracoccidioides susceptibility testing. J Clin Microbiol 2013;51:1250-2.

[28] Li DD, Deng L, Hu GH, Zhao LX, Hu DD, Jiang YY, et al. Using Galleria mellonellaCandida albicans infection model to evaluate antifungal agents. Biol Pharm Bull 2013;36:1482-7.

[29] Megaw J, Thompson TP, Lafferty RA, Gilmore BF. Galleria mellonella as a novel in vivo model for assessment of the toxicity of 1-alkyl-3-methylimidazolium chloride ionic liquids. Chemosphere 2015;139:197-201.

[30] Liu FF, Pu L, Zheng QQ, Zhang YW, Gao RS, Xu XS, et al. Calcium signaling mediates antifungal activity of triazole drugs in the aspergilli. Fungal Genet Biol 2015;81:182-90.

[31] Buissa-Filho R, Puccia R, Marques AF, Pinto FA, Muñoz JE, Nosanchuk JD, et al. The monoclonal antibody against the major diagnostic antigen of Paracoccidioides brasiliensis mediates immune protection in infected BALB/c mice challenged intratracheally with the fungus. Infect Immun 2008;76:3321-8.

[32] Thomaz L, Apitz-Castro R, Marques AF, Travassos LR, Taborda CP. Experimental paracoccidioidomycosis: alternative therapy with ajoene, compound from Allium sativum, associated with sulfamethoxazole/trimethoprim. Med Mycol 2008;46:113-18.

[33] Kaminagakura E, Bonan PR, Jorge J, Almeida OP, Scully C. Characterization of inflammatory cells in oral paracoccidioidomycosis. Oral Dis 2007;13:434-9.

[34] Souza AC, Nascimento AL, de Vasconcelos NM, Jerônimo MS, Siqueira IM, R-Santos L, et al. Activity and in vivo tracking of amphotericin B loaded PLGA nanoparticles. Eur J Med Chem 2015;95:267-76.

[35] Naranjo TW, Lopera DE, Diaz-Granados LR, Duque JJ, Restrepo AM, Cano LE. Combined itraconazole-pentoxifylline treatment promptly reduces lung fibrosis induced by chronic pulmonary paracoccidioidomycosis in mice. Pulm Pharmacol Ther 2011;24:81-91.

[36] Kelly J, Kavanagh K. Caspofungin primes the immune response of the larvae of Galleria mellonella and induces a non-specific antimicrobial response. J Med Microbiol 2011;60:189-96.

[37] Mesa-Arango AC, Scorzoni L, Zaragoza O. It only takes one to do many jobs: amphotericin B as antifungal and immunomodulatory drug. Front Microbiol 2012;3:286.

[38] Fuchs BB, Li Y, Li D, Johnston T, Hendricks G, Li G, et al. Micafungin elicits an immunomodulatory effect in Galleria mellonella and mice. Mycopathologia 2016;181:17-25. Erratum in: Mycopathologia 2016;181:27. 